\title{
Review on Epidemiology and Public Health Importance of Swine Flu
}

\author{
Tsedalu Yirsa ${ }^{1}$, Eyachew Ayana ${ }^{2},{ }^{*}$ Ayalew Negash ${ }^{3}$, BirhanuHailu $^{5}$, Girma Birhan $^{4}$, Hanna Tesfaye $^{3}$
}

${ }^{1}$ Candidate of Veterinary medicine, Faculty of Veterinary Medicine, Samara University, Samara, Ethiopia.

${ }^{2}$ Candidate of Veterinary medicine, College of Veterinary Medicine and science, University of Gondar, P.O. Box. 196, Gondar, Ethiopia.

${ }^{3}$ Lecturer at University of Gondar, College of Veterinary Medicine and science, University of Gondar, P.O. Box. 196, Gondar, Ethiopia.

${ }^{4}$ Assistant Professor of Veterinary Medicine at University of Gondar, College of Veterinary Medicine and science, University of Gondar, P.o. box. 196, Gondar, Ethiopia;5 Assistant Professor of Veterinary. Epidemiology at Samara University, Faculty of Veterinary Medicine, Samara University, Samara, Ethiopia.

"Corresponding author: Ayalew negash, Lecturer at University of Gondar, College of Veterinary Medicine and science, University of Gondar, P.O. Box. 196, Gondar, Ethiopia; Tel: +251 588119013; E-mail: ayalewnegash2014@gmail.com

Citation: Yirsa T, Ayana E, Negash A, Hailu B, Birhan G, Tesfaye H (2017) Review on epidemiology and public health importance of swine Flu. Arch Vet Sci, 2017: VST-115. DOI:10.29011/AVST-115/100015

Received Date: 24 April, 2017; Accepted Date: 1 May, 2017; Published Date: 8 May, 2017

\begin{abstract}
The world is facing challenges from both new and re-emerging diseases and Influenza virus is one of the main causes of such diseases. The virus has the ability to mutate into a form that spreads efficiently among animals and humans. Swine influenza is a highly contagious and economically important disease of pigs. It is caused by type influenza viruses with main subtypes of H1N1, H1N2, H3N2 and H3N1. These are the main subtypes in endemic areas in pig populations. Human and avian influenza viruses can infect pigs and can give rise to novel reassortants. The virus enters in to the respiratory tract through different routes and attaches to the epithelial cells on the lining of the tract and replicates. Replication of the virus and action of immune cells together disrupts the cells on the lining of the respiratory tract. The disease has short incubation period with clinical signs of fever, lethargy, anorexia, weight loss, and coughing, sneezing, nasal and ocular discharge, conjunctivitis and labored breathing. Influenza A viruses infects a large variety of animal species including humans, pigs, horses, sea mammals and birds. Transmission of the virus from pigs to humans is not common. People with regular exposure to pigs are at increased risk of swine flu infection. Swine flu rarely passes from human to human. Symptoms of zoonotic swine flu in humans are in general, namely chills, fever, sore throat, muscle pains, severe headache, coughing, weakness and discomfort. The Centers of Disease Control and Prevention recommends real time polymerase chain reaction as the method of choice for diagnosing H1N1. Prevention of swine influenza has three components: prevention in swine, prevention of transmission to humans, and prevention of its spread among humans. If a person becomes sick with swine flu, antiviral drugs used in human influenza treatment are not generally administered to swine, but Antibiotics may be used to control secondary infections.
\end{abstract}

Keywords: Epidemiology, Human, Public Health, Pig, Swine Flu (H1N1), Reassortment

\section{Introduction}

Livestock diseases that have devastating outcomes on animal health and that impact on national and international trade remain endemic in many parts of the world [1].The most recent new emerging infections caused by influenza viruses are avian and swine influenza. These emerging diseases are highly fatal infectious diseases with a pronounced public and economic importance. The virus has the ability to mutate into a form that spreads ef- ficiently among animals and humans. The global spread of highly pathogenic avian influenza H5N1 in poultry, wild birds, and humans poses a pronounced panzootic threat and a serious of public health risks [2].

Swine influenza is an acute respiratory disease caused by influenza a viruses that circulate among pigs [3]. The morbidity rate is usually high with low case fatality rate. More severe outbreaks have been observed with reduced growth rates in young pigs which cause high economic losses [4]. However, pigs can also be infected with other subtypes of influenza a viruses. Pig plays a substantially important role in the ecology of influenza A virus as they can act 
Citation: Yirsa T, Ayana E, Negash A, Hailu B, Birhan G, Tesfaye H (2017) Review on epidemiology and public health importance of swine Flu. Arch Vet Sci, 2017: VST-115.

as interspecies transmissions [5]. When co-infections among human, avian or swine influenza viruses occur within a specific host, any new subtype can be produced by antigenic reassortment [6]. Swine influenza viruses occasionally affect other species including turkeys, mink, ferrets and humans [7].

Influenza viruses are transmitted in droplets and aerosols created by coughing and sneezing, and by contact with nasal discharges, either directly or on fomites [8].It infects the epithelial lining of the respiratory tract producing clinical signs consisting of cough, fever, lethargy, anorexia, sneezing, nasal discharge, elevated rectal temperatures, breathing difficulty and depressed appetite [9].In people, clinical cases have tended to resemble human seasonal influenza. Most of these cases were not life-threatening, although serious and fatal illnesses may occur [9]. Swine influenza viruses are not usually transmitted efficiently in human population. Most infections are limited to the person who had contact with pigs, although they occasionally spread to family members or others in close contact [10].

Large propagated outbreak was reported as a result of person-to-person transmission at a military base in the 1970s, but the virus did not spread to the community [11]. Nevertheless, these viruses are capable of adapting to humans in rare instances. The 2009-2010 human pandemic was caused by a virus that appears to have resulted from genetic reassortment between North American and Eurasian swine influenza viruses [12].This virus now circulates in human populations worldwide. People have transmitted it to herds of pigs, and it has reasserted with various swine influenza viruses [13]. These events and other changes in swine influenza viruses have generated increased viral diversity and as a result of this, effective vaccination of pigs has become more difficult [8]. The number of swine influenza cases reported in humans has also increased recently, particularly in the USA, where many infections acquired from pigs at agricultural fairs [10].There is no clear information for the increased number of cases whether due to genetic changes in the viruses circulating among pigs, increased surveillance for novel influenza viruses in humans, or a combination of these factors $[8,10]$.

Even though there are several written documents, there is limited organized information on epidemiological factors of swine flu and its public health importance. Consequently, this review will address the information gap on epidemiology of swine flu and its zoonotic importance. Keeping this view, the objectives this review are:

- To review the epidemiological factors and public health importance of swine flu.

- To forward some recommendation about swine flu control options

\section{Literature Review}

\section{Historical Perspective}

Swine Influenza Virus (SIV) is any strain of influenza family of viruses that is endemic in pigs. As of 2009, the known SIV strains include influenza $\mathrm{C}$ and subtypes of influenza $\mathrm{A}$ known as H1N1, H1N2, H2N1, H3N1, H3N2, and H2N3(Kothalwala, 2006). Swine flu is not a new type of flu instead it was first diagnosed in the year 1918 in Spain and was thought to be transmitted from pigs to humans (Olsen, 2002). Spanish flu caused death of 20-40 million of population worldwide. In 1930, first swine influenza was isolated in a pig and classic SIH1N1 strain (A/Swine/Iowa/30) prototype was transmitted to other pigs for experimental analysis and characterization [14]. Serially, in 1950s to 1970s influenza A affected other regions of the world like Asian flu ,1957 and Hong Kong flu ,1968 [15]. In 1970, avian and human influenza (H3N2) transmission to pig was observed and then, in 1977a landmark in the swine influenza history affecting Russia. In 2009, H1N1 was first diagnosed in two children of Mexico having no exposure to the pig by CDC. It was declared as pandemic by WHO in the same year because of several deaths worldwide [16].

\section{Etiology}

Influenza virus is a negative sense RNA virus of the family Ortho myxoviridae with three genera: Influenza A, B and C [17]. Influenza viruses are classified into subtypes based on two surface proteins: heamagglutinin (HA) and neuraminidase (NA). A virus that has a type $1 \mathrm{HA}$ and type $2 \mathrm{NA}$, for example, would have the subtype H1N2. At least 16 types of hemagglutinins (H1 to H16), and 9 neuraminidases (N1 to N9) are known to exist in birds, and two additional HA and NA types occur in bats, while small subsets of avian subtypes circulate in other mammals [18]. Swine influenza viruses belong to the species influenza a virus and other influenza A viruses infects birds, equids, humans and dogs. Most frequently identified subtypes of SIV in pigs includes classical and avian H1N1, human (hu) H1N1 and H1N2,reassortant (r) H3N2 and rH1N2 [19]. Other subtypes that have been identified in pigs include rH1N7, rH3N1, H2N3, avian (av) H4N6, avH3N3, and avH9N2 [3].

In pigs, four main influenza a virus subtypes H1N1, H1N2, $\mathrm{H} 3 \mathrm{~N} 2$ and H7N9 are the most common strains worldwide. H3N2 evolved from $\mathrm{H} 2 \mathrm{~N} 2$ by antigenic shift [20]. Every year new strains of the virus emerge as its genes undergo continuous point mutations leading to an antigenic drift, help virus evade host defenses [21].The currently circulating strain of swine origin influenza virus of the H1N1 strain has undergone triple reassortment and contains genes from the avian, swine and human viruses [22,23].Type B and type $\mathrm{C}$ influenza viruses are not classified in to subtype. Sero- 
Citation: Yirsa T, Ayana E, Negash A, Hailu B, Birhan G, Tesfaye H (2017) Review on epidemiology and public health importance of swine Flu. Arch Vet Sci, 2017: VST-115.

logical and virological evidence indicates that influenza B and C viruses from humans can occasionally infect pigs [24-26].

\section{Pathogenesis}

After the entry of influenza into the respiratory tract through different routes it attaches to the epithelial cells on the lining of the tract and it replicates. Replication of the virus and action of immune cells together disrupts the cells on the lining of the respiratory tract [27]. SIV infects the epithelial lining of the respiratory tract, characterized by multifocal well-demarcated purplish-red lesions in the cranioventral areas of lung lobes, and induced microscopic lesions consist of epithelial disruption and attenuation in the bronchioles with later found hyperplasic proliferation and bronchiolitis obliterans [28].

\section{Clinical signs}

Although the incubation period for swine influenza in people is unknown, influenza generally becomes apparent within a few days of exposure in all mammals. Clinical signs seem to appear in approximately 2-3 days in cases caused by triple reassortant H3N2 swine influenza viruses [29]. Clinical signs usually appear within 1-3 days in pigs infected with most swine influenza viruses are fever, lethargy, anorexia, weight loss, and coughing, sneezing, nasal and ocular discharge, conjunctivitis and labored breathing [30]. All of these signs do not occur in all infected animals. Depending on the production system, illness may be seen only in certain age groups, while other animals remain asymptomatic [31].

\section{Epidemiology}

Influenza a viruses of subtypes H1N1 and $\mathrm{H} 3 \mathrm{~N} 2$ have been reported widely in pigs, associated frequently with clinical disease. These include classical swine H1N1, avian H1N1, and avian and human $\mathrm{H} 3 \mathrm{~N} 2$ viruses. These viruses have remained largely endemic in pig populations world-wide and have been responsible for one of the most prevalent respiratory diseases in pigs [32]. Sero-surveillance results in Great Britain indicated that more than half of adult pigs in the national population had been infected with one or more influenza A viruses during their lifetime, including $14 \%$ of pigs which had been infected with influenza viruses of both human and swine origin [33]. The most important epidemiological factors that exacerbate the disease epidemics in swine are reviewed as follows.

\section{Geographical distribution}

Swine influenza was first proposed to be a disease related to human flu during the $1918 \mathrm{flu}$ pandemic, when pigs became ill at the same time as humans [34].The disease has been reported from North and South America, Europe, parts of Asia and Africa. Swine influenza viruses are thought to be enzootic in most areas that have dense populations of pigs, but they might remain undetected in some regions, as infected herds can be asymptomatic or have only mild clinical signs [35].

The classical H1N1 swine influenza virus was the major virus among swine populations in North America for approximately 70 years. Some $\mathrm{H} 3$ viruses acquired from humans were also found at low levels during this time, but they did not become established as stable lineages in pigs. Triple re-assorting H3N2 viruses first emerged in North American pigs in the late 1990s, mainly in the U.S. Midwest, and spread to other regions [36]. H3N2 reasserted from human, swine and avian viruses, have become a major cause of swine influenza in North America and reassortment between H1N1 and H3N2 producesH1N2 [14].

Different swine influenza viruses circulate in Europe and avian-origin $\mathrm{H} 1 \mathrm{~N} 1$ virus entered European swine populations in the late 1970s, circulated after this time [37,38]. Various humanorigin $\mathrm{H} 3 \mathrm{~N} 2$ viruses were also detected in pigs between the mid1970s and mid-1980 [39]. Several H1N2 viruses have also been found, either transiently or long-term, although they are overall less common than other subtypes. Particularly unique variant was an H1N7 virus, which was apparently a reassortant between swine and equine influenza viruses [37].

\begin{tabular}{|c|c|c|}
\hline Subtype & Location & Comments \\
\hline \multirow{6}{*}{ H1N1 } & $\begin{array}{l}\text { North } \\
\text { America }\end{array}$ & $\begin{array}{l}\text { Classical virus, first isolated in } \\
1930 \text { in North America }\end{array}$ \\
\hline & Europe & \\
\hline & Asia & \\
\hline & South America & \\
\hline & Europe & $\begin{array}{l}\text { "Avian-like" virus, first isolated in } \\
1979\end{array}$ \\
\hline & Asia & $\begin{array}{c}\text { "Avian-like" virus, first isolated in } \\
1993\end{array}$ \\
\hline \multirow{6}{*}{ H3N2 } & Asia & $\begin{array}{c}\text { "Human-like" virus, first isolated in } \\
1970 \text { in Asia }\end{array}$ \\
\hline & Europe & \\
\hline & North America & \\
\hline & South America & \\
\hline & Africa & \\
\hline & Asia & $\begin{array}{l}\text { "Avian-like" virus, first isolated in } \\
1978\end{array}$ \\
\hline H1N2 & $\begin{array}{l}\text { Asia } \\
\text { Europe }\end{array}$ & $\begin{array}{c}\text { "Classical/human-like" reassortant } \\
\text { in Japan } \\
\text { Human-human-like reassortant in } \\
\text { Great Britain }\end{array}$ \\
\hline
\end{tabular}

Table-1: phenotypes of influenza a viruses infecting pigs endemically world-wide.

\section{Source: [33].}

TRIG-containing viruses do not circulate at present in Europe, and virus diversity is not thought to be as extensive as in 
Citation: Yirsa T, Ayana E, Negash A, Hailu B, Birhan G, Tesfaye H (2017) Review on epidemiology and public health importance of swine Flu. Arch Vet Sci, 2017: VST-115.

North America. During surveillance of several countries in 20062008 , only $3 \%$ of the viruses isolated from pigs were novel [39]. Some viruses' infected Asian pigs only transiently, and different swine influenza viruses may predominate in different regions. One notable Asian-origin H1N2 virus caused a major outbreak in Japan in 1989-1990, became established in Japanese swine populations, and has spread to some other countries [38].

At present, there is little information about swine influenza viruses in Mexico, Central and South America, or Africa. H3N2 and H1N1 viruses are known to circulate in Latin America, but genetic characterization has rarely been reported. One H3N2 virus isolated from an outbreak of respiratory disease in Argentina was of wholly human influenza virus origins, although it was highly transmissible in pigs [40]. H1 viruses were documented in one report from Africa, and a recent study from Cameroon found the 2009 pandemic H1N1 virus in free-range swine. This is also likely to be true of other regions and continents [41].

\section{Host range}

Influenza A viruses infects a large variety of animal species including humans, pigs, horses, sea mammals and birds [42,43]. Given the world-wide interaction between humans, pigs, birds and other mammalian species, there is high potential for cross-species transmission of influenza viruses in nature [43]. Swine influenza viruses mainly affect pigs, but some viruses can also cause disease in turkeys, ferrets and mink [44].

One H1N1swine influenza virus, which was a virulent for both poultry and pigs, was isolated from a duck in Hong Kong, and ducks can be infected experimentally. Infections have also been reported in calves [45]. In a recent study, antibodies to $\mathrm{H} 3$ viruses found in cattle might have been caused by exposure to swine influenza viruses, although definitive identification of the virus source was not possible [46].Pigs have unique characteristic of being host to both human as well as avian species; serving as mixing host's, in which new strains adapted to humans are created [11].

\section{Genetic variation}

Influenza viruses undergo change through the process of antigenic drift and antigenic shift. Antigenic drift is a series of point mutations which results in a different variant of the virus while antigenic shifts are dramatic changes where a new virus emerges from the reassortment of genes of two different viruses resulting in a new $\mathrm{H}$ or $\mathrm{N}$ component. Therefore, the rate of antigenic drift has been thought to be significantly slower in pigs than in humans, but now it is clear that antigenic drift as well as shift also occur in pig populations [20]. The novel H1N1 is formed due the triple reassortment of gene segments from already existing influenza strains; from North America and circulating H1N1 strains among swine's from Europe and Asia [47].
The HA gene of both classical and avian like swine H1N1 viruses is undergoing genetic drift, being more marked in the latter. However, genetic drift in HA gene of swine H1N1viruses is confined generally to regions unrelated to antigenic Sites [48], which is in marked contrast to genetic drift inHAgeneofhumanH1N1viruses. The limited antigenic variation in HA gene of swine viruses is probably due to lack of significant immune selection in pigs because of availability of no immune pigs. The HA genes of classical swine H1N1influenza virus isolates in North America have remained conserved both genetically and antigenic ally over period of at least 25 years. But viruses distinguishable antigenic ally, although closely related, have been reported [49].Influenza viruses of H3N2 subtype continue to circulate widely in pigs world-wide. The majority of these viruses are antigenically related closely to early human strains. The limited immune selection in pigs facilitates the persistence of these viruses, which may in future transmit to a susceptible human population [24].

\section{Transmission}

In mammals, influenza viruses are transmitted in droplets and aerosols created by coughing and sneezing, and by contact with nasal discharges, either directly or by fomites [8]. The main route of transmission is through direct contact between infected and uninfected animals. As the pigs are raised in very close proximity to each other, the direct transfer of the virus probably occurs either by pigs touching noses, or through dried mucus. Airborne transmissions through the aerosols produced by pigs coughing or sneezing are also an important means of infection [20].

Pigs serve as major reservoirs of H1N1andH3N2 influenza viruses and are often involved in interspecies transmission of influenza viruses. The maintenance of the seviruses in pigs and frequent introduction of new viruses from other species could be important in the generation of pandemic strains of human influenza. Isolation of swine H1N1 virus from turkeys was subsequently transmitted to a laboratory technician. These findings raise the possibility that viruses from pigs, humans, turkeys and ducks may serve as source of virus for each other's [50]. In Europe, avian H1N1 viruses were transmitted to pigs established as table lineage and have subsequently been reintroduced to turkeys from pigs, causing economic losses [51].

Transmission from humans to pigs occurs and rarely from avian species. Once a herd is infected with a virus which is able replicate, irrespective of its origin, the virus persists through the production of young susceptible pigs and the introduction of new stock, often leading to the herd becoming infected endemically. Transmission of virus from another species to pigs may lead eventually to the establishment of a new virus lineage in pigs [33]. 
Citation: Yirsa T, Ayana E, Negash A, Hailu B, Birhan G, Tesfaye H (2017) Review on epidemiology and public health importance of swine Flu. Arch Vet Sci, 2017: VST-115.

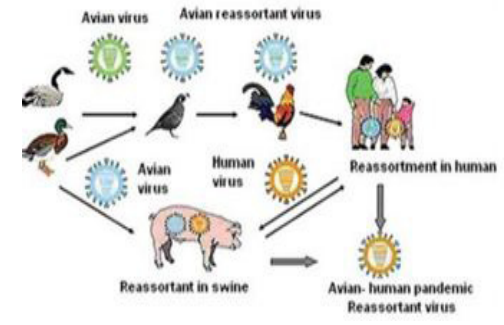

Figure -1: Swine flu transmission [52].

There are a number of factors which increase the likelihood of occurrence of dangerous pathogens emerging from various farming units. In the last fifty years, poultry and pig farms have changed from small-scale farms to industrial-scale operations in which thousands of animals of similar genotypes are raised for food production [53]. A large-scale industrial farm is a perfect breeding ground for the emergence and spread of influenza viruses. The sheer numbers of animals on industrial farms facilitates the rapid transmission and mixing of viruses [54]. Herd size is positively correlated with prevalence of infectious agents [55]. This may be because of increased risk of introduction of infectious pathogens from outside the herd as a greater number of new pigs are introduced to the herd and greater risk of transmission within the herd [56].

Overcrowding results in more opportunities for direct noseto-nose contact between pigs. It also results in greater spread of pathogens in aerosol form between pigs in the same unit [55]. The confinement of thousands of animals requires ventilation with high volume fans in order to control heat and humidity. This results in considerable movement of air, potentially carrying pathogens, into the outside environment. The proximity of intensive pig farms and intensive poultry farms increases the risks of viral recombination and the emergence of new virulent flu strains. Animals can be transported over long distances and also undergo substantial mixing with animals from different herds and geographical areas during transport, creating a higher risk of pathogen transmission. The open-truck transport of animals from farms to slaughterhouses creates a biosecurity risk [57]. In addition, the stress which animals experience during transport can weaken their immune systems and make them more susceptible to disease [55].

Seasonality varies with the climate and type of production system. Therefore under traditional production systems, annual outbreaks occur mainly during the colder months in temperate regions, but may be seen year round in tropical and subtropical climax. Outbreaks can occur at any time of the year under intensive farming practices, although there may be seasonal peaks when rapidly changing outside temperatures makes it more difficult to control climatic conditions in the barn [31].

\section{Morbidity and Mortality}

Swine influenza viruses are common in pig populations, and many farms worldwide have been infected with at least one virus.
A number of studies report seroprevalence rates of approximately $20-60 \%$, with some studies reporting higher or lower values. In Europe, virus prevalence is generally higher in intensive swineraising regions [37]. In the classical picture of influenza, up to $100 \%$ of the animals in a naive herd may become ill, and if the virus infects a population without immunity, it may cause an epizootic with rapid transmission in pigs of all ages. In other cases, the virus can persistin a herd [58].The main economic impact is usually from reduced weight gain and a longer time to reach market weight. Mortality rates are generally low; in uncomplicated cases, the case fatality rate varies from less than $1 \%$ to $4 \%$, and most animals recover within 3-7 days. However, outbreaks can differ in severity, depending on management factors, co-infections with other pathogens and other stressors [58].

\section{Diagnosis}

A presumptive diagnosis is performed by observing the clinical and pathological findings, while confirmatory diagnosis include detection of the virus, viral nucleic acid or antigen-antibody reaction of serologic assays $[2,20]$.Swine influenza viruses can be isolated in embryonated chicken eggs or cell cultures. These viruses can be isolated from lung tissues at necropsy, and from nasal or pharyngeal swabs collected from acutely ill pigs [59, 60]. The primary serological test for detection of swine influenza virus antibodies is the HI test conducted on paired sera. Additional serological tests that have been described are the agar gel immune diffusion test, indirect fluorescent antibody test, virus neutralization, and ELISA [2,61]. Immuno histochemistry can identify antigens in lung tissue samples, nasal epithelial cells or bronchoalveolar lavage fluids. Antigens can also be detected with ELISAs. RTPCR assays, which can also detect viral RNA in tissue samples or respiratory fluids, are often used in influenza diagnosis. It is the most sensitive and very specific for the detection of H1N1 virus $[59,60]$.

\section{Prevention and Control}

Animals with influenza are usually treated with supportive care and rest. Antibiotics may be used to control secondary infections. Antiviral drugs used in human influenza treatment are not generally administered to swine [62]. Methods of preventing the spread of influenza among swine include facility management, herd management, and vaccination. Facility management includes using disinfectants, and ambient temperature to control viruses in the environment [63]. Herd Management measures such as all-in/ all-out production help prevent the introduction of viruses. Isolating newly acquired pigs, biosecurity plans and testing before release also reduces the risk of transmission to the rest of the herd. Sanitation and routine hygiene; helps prevent transmission on fomites and mechanical vectors [25].

SIV vaccines used nowadays may not induce strong immunity nor completely eliminate clinical signs of infection in swine. 


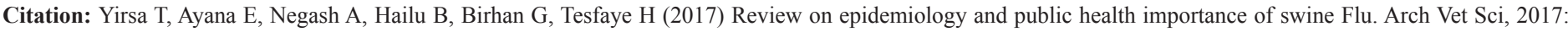
VST-115.

Hence, a vaccine inducing cross protective immunity between different subtypes and strains is highly desirable as H1N1, H3N2, and H1N2 subtypes, with antigenically different haemagglutinins, are currently circulating in pigs globally. But, with the increasing number of novel subtypes and genetic variants, the control of swine influenza using vaccination strategy alone may not be a viable option. Vaccination of pigs is not $100 \%$ effective, but can reduce the levels of virus shed by infected animals, and thus reduce the potential for human exposure and zoonotic infection [2].

\section{Economic importance and Major potential threats of swine flu in Africa}

Influenza-related diseases have continued to remain a source of worry and panic in the Nigerian livestock sector, because of its zoonotic and enormous economic losses associated with the diseases [64].Swine flu which has become a global threat is gradually spreading to unaffected regions of the world. The outbreak of this disease in a continent like Africa and particularly Nigeria, is already struggling with social andeconomic problems [65]. Even though farmers in Mubi region had anticipated the outbreak of Swine flu disease, there were no any economic losses incurred as a result of panic and scare. It is therefore, recommended that news of anticipated outbreak of disease of health economic importance such as swine flu be managed by trained personnel who should give more emphasis on biosecurity measures that could help in preventing a possible outbreak of such diseases in the region [64].

\section{Public health importance of swine flu}

Emerging zoonotic diseases have causing significant morbidity and mortality in humans and animals. Swine flu is a highly infectious emerging viral zoonosis of global significance. It is caused by a new strain of influenza a virus. The disease is reported from many countries of the world including India. Humans can get infection through close contact with infected pig. The disease spreads from person to person through coughing, sneezing, contact or sometimes through contaminated fomites. Diseased person can transmit the infection to pig [66].Swine influenza virus is common throughout pig populations worldwide. Transmission of the virus from pigs to humans is not common and does not always lead to human flu, often resulting only in the production of antibodies in the blood. If transmission does cause human flu, it is called zoonotic swineflu [67].

Swine influenza virus infections in humans have been reported in the United States, Canada, Europe, and Asia. There are no unique clinical features that distinguish swine influenza in humans from typical influenza. Although a number of the case patients had predisposing immune compromising conditions, healthy persons are also clearly at risk for illness and death from swine influenza. The high proportion of fatalities in this case series likely reflects a strong case ascertainment bias [29]. The majority of case patients reported contact with pigs, consistent with sero-epidemiological studies that have demonstrated increased rates of swine influenza virus infection in people with occupational swine exposure, and those who work with swine may serve as a bridge for transmission of the virus to their communities [12].

Around the mid-20th century, identification of influenza subtypes became possible, allowing accurate diagnosis of transmission to humans. Since then, only 50 such transmissions have been confirmed. These strains of swine flu rarely pass from human to human. Symptoms of zoonotic swine flu in humans are similar to those of influenza and of influenza-like illness in general [10]. Infections with various $\mathrm{H} 1 \mathrm{~N} 1, \mathrm{H} 3 \mathrm{~N} 2$ and $\mathrm{H} 1 \mathrm{~N} 2$ swine influenza viruses are reported sporadically in humans. It is possible that certain genotypes are more likely to infect people [29]. There is evidence that suggests limited person-to-person transmission of some swine influenza viruses, including one large outbreak at the Fort Dix military base in the 1970s. This was the only virus known to have become adapted to humans in the 2009 pandemic H1N1 virus [10,29].

\section{Overview of 2009 Swine Flu Pandemic}

The 2009 flu pandemics of global outbreak of a new strain of an influenza A Virus subtype H1N1, referred to as the novel H1N1, first identified in April 2009, and commonly called swine flu. It is thought to be a reassortment of four known strains of influenza A virus: one endemic in humans, one endemic in birds, and two endemic in pigs. The outbreak began in Mexico, with evidence that Mexico was already in the midst of an epidemic for months before the outbreak was recognized [68].

Beginning in March 2009, an outbreak of influenza in North America was found to be caused by a new strain of influenza virus, designated Influenza H1N1 2009. On April 9, 2009 it became apparent to public health officials in Mexico City that an outbreak of influenza was in progress late in the influenza season [66]. On April 17, two cases in children were also reported in California near the Mexican border. The current outbreak of swine influenza A (H1N1) evolved so rapidly that as on 29 April 2009, nine countries officially reported with confirmed cases of swine influenza A/ H1N1infection [69].

Of these, Mexico, United State, Austria, Canada, Germany, Israel, New Zealand, Spain and the United Kingdom have reported laboratory confirmed human cases and deaths due to rapidly progressive pneumonia, respiratory failure and acute respiratory distress syndrome (ARDS) [68]. WHO declared ever high stages on its pandemic scale-alert 6, designating the Influenza H1N1 2009 a potential threat to worldwide health and declared the outbreak as Public Health Emergency of International Concern (PHEIC).In India total confirmed cases and total deaths crossed to a level where the threat of full blown epidemics was very rear [69]. 
Citation: Yirsa T, Ayana E, Negash A, Hailu B, Birhan G, Tesfaye H (2017) Review on epidemiology and public health importance of swine Flu. Arch Vet Sci, 2017: VST-115.

\section{Current Status of Swine Flu in Human}

Influenza a $\mathrm{H} 3 \mathrm{~N} 2$ variant viruses with the matrix gene from the $2009 \mathrm{H} 1 \mathrm{~N} 1$ pandemic virus were first detected in people in July 2011. The viruses were first identified in U.S. pigs in 2010. In 2011, 12 cases of H3N2v infection were detected in the United States [70]. In 2012, 309 cases of H3N2v infection across 12 states were detected. In 2013, 19 cases of H3N2v across five states were detected. Infections with $\mathrm{H} 3 \mathrm{~N} 2 \mathrm{v}$ have mostly been associated with prolonged exposure to pigs at agricultural fairs. Currently, H1N1 and $\mathrm{H} 3 \mathrm{~N} 2$ are two subtypes of influenza a viruses circulating in humans [71].

In 2014, in India, a total of 218 people died from the H1N1 flu, and recorded 837 laboratory confirmed cases in the year. Every year, there was a rise in number of cases and deaths during winter as temperature affects virus. During 2014-15winter, there was a spurt in cases at the end 2014. In 2015, the outbreak became widespread through India. Swine flu outbreaks were reported in Nepal in the spring of 2015. As of April 21, 2015 the disease has claimed 26 lives in the most severely affected district, Jajarkot in Northwest Nepal. There were also seven cases of Swine flu reported in Punjab province of Pakistan mainly in the city of Multan in January 2016.Cases of Swine Flu have also been reported in Lahore(https://en.wikipedia.org/wiki/Swine_influenza).

Children younger than 2 years old; adults 65 years of age and older; pregnant women; people who have medical conditions (including: Asthma; Chronic lung, Heart, Kidney and Liver disorders), and weakened immune system a reat high risk of developing flu-related complications [70]. People who work with swine, especially those with intense exposures, are also at increased risk of zoonotic infection with influenza virus endemic in these animals, and constitute a population of human hosts in which zoonosis and re-assortment can co-occur [71].

\section{Transmission}

Human can transmit H1N1 virus to animals as well as other peoples.H1N1 virus infected person is considered potentially contagious till 7 days following the onset of illness [72].The main route of transmission is through direct contact between infected and healthy individuals. Virus is transmitted in aerosols created by coughing and sneezing, and also by contact with nasal discharges, either directly or on fomites. Humans can also contract infection from the diseased pigs [73].Spread of the H1N1 virus is thought to occur in the same way that seasonal flu spreads. Flu viruses are spread mainly from person to person through coughing or sneezing by people with influenza. Sometimes people may become infected by touching something such as a surface or object with flu viruses on it and then touching their face [74].

\section{Symptoms}

The incubation period of novel H1N1 virus appears to be 2 to 7 days. The clinical signs manifested by H1N1 include fever, sore throat, cough, shortness of breath, headache, body-aches, chills, runny nose, weakness, pneumonia, conjunctivitis, besides vomiting and diarrhea. Pneumonia is the main cause of death. Multiple organ failure may also occur [72].

\section{Diagnosis}

The diagnosis of swine flu virus is essential in patients because symptoms are almost common to all influenza infections. It can be diagnosed by molecular, and antigen-antibody based diagnostic methods. RT-PCR is one of the currently used methods of detection of swine flu. It is a type of polymerase tests that synthesizes cDNA from RNA. For pandemic H1N1 the targets include HA and matrix gene [75].HI test utilizes the HA protein on the surface of the virus that binds to circulating antibodies. This prevents the virus to bind to the erythrocytes, forming erythrocy tehaemagglutinin lattice. This property is known as haemagglutination [76]. Virus neutralization test is also a reaction between living viruses mixed in serum and the susceptible host cells [77].

Rapid influenza detection tests (RIDTs) is also known as point of care tests. It takes less than 30 minutes in diagnosing a disease and is commercially available. The sensitivitiy of RIDT are $50-70 \%$ as compared to real time diagnosis. These tests can diagnose only influenza A type viruses or both $\mathrm{A}$ and $\mathrm{B}$ types but cannot distinguish between them [78].Biosensors are remarkably known to convert biological signal into electrical, optical signals. Analysis is based on affinity reactions including DNA-DNA, antibody-antigen, enzyme substrate and protein-DNA [79].

\section{Treatment and Prevention}

Supportive care for uncomplicated influenza in humans includes fluids and rest. Additional support retreatments and antibiotics can be used to treat or prevent secondary bacterial pneumonia, and mechanical ventilation [33]. There are four different antiviral drugs that are licensed for use in the US for the treatment of influenza: amantadine, rimantadine, oseltamivir and zanamivir. At this time, CDC recommends the use of oseltamivir or zanamivir are best for the treatment and prevention of infection with swine influenza virus (www.cdc.gov/flu/swine/recommendations. $\mathrm{htm}$ ). Protective measures for zoonotic influenza viruses include sanitation and hygiene, avoidance of contact with sick animals, and the use protective clothing and gloves when working with infected pigs [8]. Swine influenza viruses are not likely to be present in retail meat [35].Any viruses that survived long enough to reach consumers could be inactivated by cooking pork [8].

In a comparison of various strategies for the control of pandemic in the western countries using mathematical modeling, it was suggested that hospital and community transmission control measures alone can be highly effective in reducing the impact of a potential flu pandemic [80]. These includes: symptomatic people should stay at home, avoid crowds, and take off from work 
Citation: Yirsa T, Ayana E, Negash A, Hailu B, Birhan G, Tesfaye H (2017) Review on epidemiology and public health importance of swine Flu. Arch Vet Sci, 2017: VST-115.

or school until the disease is no longer transmittable. Sneezing, coughing, and nasal secretions need to be kept away from other people; simply using tissues and disposing of them will help others [8]. There is also availability of new influenza vaccine preparation which is administered intradermally. It works like the shot except the administration is less painful and is approved for ages 18-64 years. CDC recommendations include a flu shot to everyone 6 months old and older to prevent or reduce the chance of getting the flu [74].

\section{Conclusion and Recommendations}

Swine flu is an acute respiratory disease of pigs caused by swine influenza viruses. It is highly contagious viral infections that can have significant economic and public health importance. Four main virus subtypes occurring in pigs include H1N1, H1N2, $\mathrm{H} 3 \mathrm{~N} 2$, and H3N1, though most of the recently isolated are the H1N1 viruses. Only people who used to have direct contact with pigs were observed to get swine flu in the past. But, H1N1 virus is a new swine flu virus and it contains the genetic material of swine, bird and human influenza virus; has acquired the ability of rapid human to human spread thus causing pandemic situation in several countries around the world. It spreads mainly by coughing, sneezing, and close contact. Rapid diagnosis of swine flu is now possible by polymerase chain reaction technique. Prevention can successfully be accomplished with vaccination, biosecurity measures and other management practices. The Center for Disease Control and Prevention gives its recommendations every year for Prevention of Swine flu and should be adopted.

Based on the above conclusions, the following recommendations are forwarded:

- Biosecurity plans including contact with feral pigs, wild birds, poultry, people, unsafe water sources that may contain viruses, and possibly even horses should be restricted.

- Quarantine; depopulation, all-in/all-out production system and test for the presence of the diseases for the newly incoming pigs should be done to prevent the introduction of viruses.

- Good hygiene, use of facemasks, and frequent hand washing with soap and water or alcohol-based hand disinfectants are also recommended.

- Symptomatic people should stay at home, avoid crowds, and take off from work or school until the disease is no longer transmittable (about two to three weeks) or until medical help and advice is sought.

\section{References}

1. Gibbs EP (2005) Emerging zoonotic epidemics in the interconnected global community. Vet. Rec 157: 673-679.

2. Olsen CW, Brown IH, Easterday BC, Van Reeth K (2006) Swine Influenza. In: Diseases of Swine, Straw B.E., Zimmerman J.J., Taylor D.J. \& D’Allaire S., eds. Ames, lowa State University Press 469: 48.
3. Olsen CW, Brown I, Easter day BC, Van Reeth K (2005) Swine Influenza. In: Diseases of Swine, Straw B., D'Allaire S., Zimmerman J. and Taylor D., eds. lowa State University Press, lowa, USA 469: 482.

4. Schultz-Cherry S, Olsen CW, Easter day BC (2013) History of swine influenza. Curr. Top. Microbiol. Immunol 370: 21-28.

5. Easter day BC, Van Reeth K (1999) Swine Influenza Disease of Swine; lowa 8th edition 277: 287.

6. Webster R, Cox N, Stohi K (2002) WHO Manual on Animal Influenza Diagnosis and Surveillance World Health Organization 15-67.

7. Yang H, Qiao C, Tang X, Chen Y, Xin X, et al. (2012) Human infection from avian-like influenza $A(\mathrm{H} 1 \mathrm{~N} 1)$ viruses in pigs, China. Emerg. Infect. Dis 18: 1144-1146.

8. Centers for Disease Control and Prevention (CDC) (2014) Seasonal Influenza. Information for health care professionals 64: 810-834.

9. Bastien N, Antonishyn NA, Brandt K, Wong CE, Chokani K, et al. (2010) Human infection with a triple-reassortant swine influenza $\mathrm{A}(\mathrm{H} 1 \mathrm{~N} 1)$ virus containing the hemagglutinin and neuraminidase genes of seasonal influenza virus. J. Infect. Dis 201: 1178-1182.

10. Epperson S, Jhung M, Richards S, Quinlisk P, Ball L, et al. (2013) Human infections with influenza A (H3N2) variant virus in the United States, 2011-2012. Clin. Infect. Dis 57: 1- 11.

11. Myers PK, Olsen CW, Gray CG (2007) Cases of swine influenza in humans: a review of the literature. Clin. Infect. Dis 44: 1084-1088.

12. Garten RJ, Davis CT, Russell CA, Shu B, Lindstrom S, et al. (2009) Antigenic and genetic characteristics of swine origin 2009 A (H1N1) influenza viruses circulating in humans. Sci 325: 197-201.

13. Rajao DS, Costa AT, Brasil BS, Del Puerto HL, Oliveira FG, et al. (2013) Genetic characterization of influenza virus circulating in Brazilian pigs during 2009 and 2010 reveals a high prevalence of the pandemic H1N1 subtype. Influenza Other Respire Viruses 7: 783-790.

14. Olsen CW (2002) "The emergence of novel swine influenza viruses in North America". Virus Research 85: 199-210.

15. Kibrom ED (2006) Influenza pandemics of the 20 century. E.I.D.J 12: 1.

16. Jafri SSI, liyas M, Idrees M (2010) "Swine flu: A threat to human health", Biotechnol and Molecular biolology Reviews 3: 46- 50.

17. Dolin R, Kasper DL, Braunwald E, Fauci AS, Hauser SL, et al. (2005) Influenza. In, Longo. Harrison's principles of internal medicine McGraw Hill 2005: 1066-1070.

18. Tong S, Zhu X, Li Y, Shi M, Zhang J, et al. (2013) new world bats harbor diverse influenza a viruses. PLoS. Pathog 9: 100-3657.

19. Gramer MR (2007) SIV: an update on circulating strains advances in diagnostic tests and interpretation of test results. In: Proceedings of the American Association of Swine Veterinarians, Orlando, Florida, USA 3-6.

20. Kothalawala H, Toussaint MJ, Gruys E (2006) an overview of swine influenza. Vet. Q 28: 46-53.

21. Glezen WP (2004) Influenza viruses. In: Feigin RD, Cherry JD, Demmler GJ, Kaplan SL, eds. Textbook of Pediatric Infectious Diseases. Saunders. Philadelphia 2024- 2040.

22. Newman AP, Reisdorf E, Beinemann J, Uyeki TM, Balish A, et al. (2008): Swine influenza A (H1N1) triple reassortant virus infection, Wisconsin. Emerg. Infect. Dis 14: 1470-1472. 
Citation: Yirsa T, Ayana E, Negash A, Hailu B, Birhan G, Tesfaye H (2017) Review on epidemiology and public health importance of swine Flu. Arch Vet Sci, 2017: VST-115.

23. Morens DM, Taubenberger JK, Fauci AS (2009) the persistent legacy of the 1918 influenza virus. NEJM 361: 225-229.

24. Brown IH, Chakraverty P, Harris PA, Alexander DJ (1995) Disease outbreaks in pigs in Great Britain to influenza a virus of H1N2 subtype. Veterinary Record 136: 328-329.

25. Dee SA (2012) Swine influenza. In: Aiello SE, Moses MA, editors. The merck veterinary manual [online]. Whitehouse Station, $\mathrm{NJ}$ : Merckand Co.

26. Hause BM, Ducatez M, Collin EA, Ran Z, Liu R, et al. (2013) Isolation of a novel swine influenza virus from Oklahoma in 2011 which is distantly related to human influenza C viruses. PLoS. Pathog 9: 1003176.

27. Wang R, Taubenberger JK (2010) Method for molecular surveillance of influenza. Expert Review of Anti- infective Therapy 8: 517-527.

28. Thacker EL, Thacker BJ, Janke BH (2001) Interaction between Mycoplasma hyopneumoniae and Swine Influenza Virus. J .Clin. Microbiol 39: $2525-2530$

29. Jhung MA, Epperson S, Biggerstaff M, Allen D, Balish A, et al. (2013) Outbreak of variant influenza $\mathrm{A}(\mathrm{H} 3 \mathrm{~N} 2)$ virus in the United States. Clin. Infect. Dis 57: 1703-1712.

30. Acha PN, Szyfres B (2003) Zoonoses and communicable diseases common to man and animals. Volume 2.Chlamydiosis, rickettsiosesand viroses. 3rd ed. Washington DC: PAHO. Scientific and Technical Publication No. 580. Influenza 155-72.

31. Janke BH (2013) Clinico pathological features of swine influenza. Curr. Top. Microbiol. Immunol 370: 69-83.

32. Rose N, Herve S, Eveno E, Barbier N, Eono F, et al. (2013) Dynamics of influenza A virus infections in permanently infected pig farms: evidence of recurrent infections, circulation of several swine influenza viruses and reassortment events. Vet. Res 4: 44-72.

33. Brown IH (2000) the epidemiology and evolution of influenza viruses in pigs. Vet. Microbiol 74: 29-46.

34. Knobler S, Mack A, Mahmoud A, Lemon S (2005) the Story of Influenza. The Threat of Pandemic Influenza: Are We Ready Workshop Summary. Washington, D.C. The Natl. Acad. Press 75.

35. Van RK (2007) Avian and swine influenza viruses: our current understanding of the zoonotic risk. Vet. Res 38: 243-60.

36. Gagnon CA, Spearman G, Hamel A, Godson DL, Fortin A, et al. (2009) Characterization of a Canadian mink H3N2 influenza A virus isolate genetically related to triple reassortant swine influenza virus. J. Clin. Microbiol 47: 796-799.

37. Brown IH (2013) History and epidemiology of swine influenza in Europe. Curr.Top. Microbiol. Immunol 370: 133-146.

38. Choi YK, Pascua PN, Song MS (2013) Swine influenza viruses: an Asian perspective. Curr. Top. Microbiol. Immunol 370: 147-172.

39. Kyriakis CS, Brown IH, Foni E, Kuntz-Simon G, Maldonado J, et al. (2011) Virological surveillance and preliminary antigenic characterization of influenza viruses in pigs in five European countries from 2006 to 2008. Zoonoses Public Health 58: 93-101.

40. Cappuccio JA, Pena L, Dibarbora M, Rimondi A, Pineyro P, et al. (2011) Outbreak of swine influenza in Argentina reveals a non-contemporary human H3N2 virus highly transmissible among pigs. J. Gen. Virol 92: 2871-2878.
41. Meseko C, Olaleye D, Capua I, Cattoli G (2014) Swine influenza in sub-saharan Africa-current knowledge and emerging insights. Zoonoses Public Health 61: 229-237.

42. Alexander DJ (1982) Ecological aspects of influenza A viruses in animals and their relationship to human influenza: A review. J.R. Soc. Med 75: 799-811.

43. Webster RG, Bean WJ, Gorman OT, Chambers TM, Kawaoka Y (1992) Evolution and ecology of influenza A viruses. Microbiol. Rev 56: $152-179$.

44. Yassine HM, Lee CW, Saif YM (2013) Interspecies transmission of influenza a viruses between swine and poultry. Curr. Top. Microbiol. Immunol 370: 227-240.

45. Butterfield WK, Campbell CH, Webster RG, Short ridge KF (1978) Identification of a swine influenza virus (Hsw1N1) isolated from a duck in Hong Kong. J. Infect. Dis 138: 686-689.

46. Lin C, Holland RE, McCoy MH, Donofrio-Newman J, Vickers ML. et al. (2010) Infectivity of equine H3N8 influenza virus in bovine cells and calves. Influenza Other Respi. Viruses 4: 357-361.

47. Brown IH, Ludwig S, Olsen CW, Hannoun C, Scholtissek C, et al. (1997) Antigenic and genetic analyses of H1N1 infuenzaA viruses from European pigs. J.Gen. Virol 78: 553-562.

48. Brown IH, Ludwig S, Olsen CW, Hannoun C, Scholtissek C, et al. (1997) Antigenic and genetic analyses of H1N1 infuenzaA viruses from European pigs. J.Gen. Virol 78: 553-562.

49. Wentworth DE, Thompson BL, Xu X, Regnery HL, Cooley AJ, et al (1994) An influenza A (H1N1) virus, closely related to swine influenza virus, responsible for a fatal case of human influenza. J. Virol 68 : 2051-2058

50. Hinshaw VS, Webster RG, Bean WJ, Downie J, Senne DA (1983) Swine influenza likes viruses in turkeys: potential source of virus for humans. Sci 220: 206-208.

51. Wood GW, Banks J, Brown IH, Strong, I, Alexander DJ (1997) The nucleotide sequence of the HA1 of The haemagglutinin of an $\mathrm{H} 1$ avian influenza virus isolate from turkeys in Germany provides additional Evidence suggesting recent transmission from pigs. Avian. Pathol 26: 347-355.

52. Rewar S, Mirdha D, Charanjeet $S$, Rewa $P(2015)$ swine-origin influenza a (h1n1) virus: a review; International Journal of Analytical, Pharmaceutical and Biomedical Sciences 4: 7 .

53. Otte J, Roland-Host D, Pofeiffer D, Soares-Magalhaw R, Rushton J, et al. (2007) Industrial livestock production and global health risk. PPLPI Research Report 7: 1-21.

54. Wuethrich B (2003) Chasing the fickle swine flu. Science 299: 15025.

55. Fablet C (2009) an overview of the impact of the environment on enzootic respiratory diseases in pigs. In: Aland, A., Madec, F. (Eds.).Sustainable animal production. Wageningen Academic Publishers $239-260$.

56. Gardner LA, Wilberg P, Mousing J (2002) Empirical and theoretical evidence for herd size as a risk factor for swine diseases. Animal health research reviews 3: 43-55

57. Graham JP, Leibler JH, Price LB, Otte JM, Pfeiffer DU, et al. (2008) The Animal-Human interface and Infectious Disease in Industrial Food Animal Production: Rethinking biosecurity and Bio containment. Public Health Reports 123: 282-299. 
Citation: Yirsa T, Ayana E, Negash A, Hailu B, Birhan G, Tesfaye H (2017) Review on epidemiology and public health importance of swine Flu. Arch Vet Sci, 2017: VST-115.

58. Brown IH (2006) (OIE/FAO/EU International Reference Laboratory for Avian Influenza). Influenza virus infections of pigs. Part 1: swine, avian \& human influenza viruses [monograph online].

59. World Organization for Animal Health (OIE) (2010) Manual of diagnostic tests and vaccines for terrestrial animals [online] Paris. OIE swine influenza.

60. Detmer S, Gramer M, Goyal S, Torremorell M, Torrison J (2012) Diagnostics and surveillance for swine influenza. Curr. Top. Microbiol. Immunol 370: 85-112.

61. Spickler AR (2009) Influenza. Center Food Security and Public Health, lowa State University.

62. Swayne DE (2008) avian influenza. In foreign animal diseases. Boca Raton, FL: United States Animal Health Association 137-146.

63. De Benedictis P, Beato MS, Capua I (2007). Inactivation of avian influenza viruses by chemical agents and physical conditions: a review. Zoonoses Public Health 54: 51-68.

64. Augustine C, Midau A, Ja'afar-Furo MR (2010) affects Of Level of Awareness of Pig Rearers about Swine Flu on Markets Prices of Pigs in Mubi Zone, Nigeria. J. Am. Sci 6: 339-342.

65. Kwaghe PV, Amaza PS, Ja'afar-Furo MR (2009) The relationship between social factors and the poverty experienced by farming households in Borno State, Nigeria. Globl. J. Age. Sci 8: 119-126.

66. Mahendra Pal, Raj Mahendra (2015) Swine Flu: A Highly Infectious Emerging Viral Zoonosis; Ethiopian International Journal of Multidisciplinary 2: 51-53.

67. Myers KP, Olsen CW, Setterquist SF, Capuano AW, Donham KJ, et al. (2006) Are Swine Workers in the United States at Increased Risk of Infection with Zoonotic Influenza Virus? Clin. Infec. Dis 42: 14-20.

68. Christman MC, Kedwaii A, Xu J, Donis RO, Lu G (2011) Pandemic (H1N1) 2009 virus revisited: an evolutionary retrospective. Infect. Genet. Evol 11: 803-811.

69. Smith GJ, Bahl J, Vijaykrishna D (2009) Dating the emergence of pandemic influenza viruses. Proc. Natl. Acad. Sci. USA 106: 1170911712.
70. Swayne DE, Aiello SE, Moses MA (2012) Overview of avian influenza. In: The Merck veterinary manual avian influenza.

71. Gray GC, McCarthy T, Capuano AW, Setterquist SF, Olsen CW, et al. (2007) Swine workers and swine influenza virus infections. Emerg. Infect. Dis 13: 1871-1878.

72. Mishra N (2011) Emerging influenza A/H1N1: Challenges and development. The Health 1: 16-22.

73. CFSPH (2009) Swine influenza. The center for food security and public health, lowa State University, Ames, Iwoa, USA 1-19.

74. Centers for Disease Control and Prevention (CDC) (2009) Press briefing transcript: CDC briefing on public health investigation of human cases of swine influenza.

75. Jiang T, Kang XP, Deng Y (2009) Development of a real time RT-PCR assay for a novel influenza A (H1N1) virus, J. Virol. Methods 2: 470473.

76. Janke BH (2000) Diagnosis of swine influenza, Journal of Swine Health and Production 2: 79-84.

77. Thomas Rowe, Abernathy RA, Hu-Primmer J, Thompson WW, Lu X, et al. (1999) Detection of antibody to avian influenza A (H5N1) virus in human serum by using a combination of serologic assay, J. Clin. Microbiol 37: 937-943.

78. Baas C, Barr IG, Fouchier RA, Kelso A, Hurt AC (2013) a comparison of rapid point of care tests for the detection of avian influenza $A(H 7 N 9)$ virus. Euro. Surveill 18: 21

79. Marrazza G, Chianella I, Mascini M (1999) Disposable DNA electrochemical sensor for hybridization detection, Biosensor Bioelectronics 14: 43-51.

80. Nuno M, Chowell G, Gumel AB (2007) Assessing the role of basic control measures, antiviral and vaccine in curtailing pandemic influenza: scenarios for the US, UK and the Netherlands. J. R. Soc. Interface 4 505-521. 